\title{
Can rt-PA be Administered to the Wrong Patient? Two Patients with Somatoform Disorder
}

\author{
Mikael S. Mouradian, Jennifer Rodgers, Jodi Kashmere, Glen Jickling, \\ Jennifer McCombe, Derek J Emery, Andrew M. Demchuk, Ashfaq Shuaib
}

\begin{abstract}
Background: Intravenous rt-PA (IV rt-PA) for acute stroke has raised many concerns, including its inadvertent use in patients presenting with acute stroke-like symptoms as the expression of their somatoform disorder. Diagnosis of the somatoform disorder is often delayed, and thrombolytics in these patients for their stroke-like presentation subjects them to risk for hemorrhage. Methods: The presentation, neurological findings, and the therapeutic decision making was audited in 85 patients who received IV rtPA for a diagnosis of acute stroke. All the surviving patients were re-examined neurologically at least three months after IV rt-PA. Baseline and follow-up brain CT scans were re-reviewed by a neuroradiologist who was blinded to clinical presentation and outcome. Patients whose clinical presentation, brain CT and neurological outcome did not fit into known or expected anatomical and clinical patterns of stroke underwent psychological assessment using the Minnesota Multiphasic Personality Inventory-2. Results: In two patients three stroke-like presentations of somatoform disorder inadvertently were treated with IV rt-PA. This was primarily caused by abbreviated neurological examination and narrow differential diagnosis. Interpretation: Patients with somatoform disorder may present with symptoms mimicking acute stroke. Under the time constraints of IV rt-PA use, a diagnosis of somatoform disorder can be missed, subjecting such patients to the potential complications of thrombolytics.
\end{abstract}

RÉSUMÉ: Le rtPA peut-il être administré au mauvais patient? Deux patients présentant un trouble somatoforme. Introduction: L'utilisation de rtPA par voie intraveineuse (IV) dans le traitement de l'accident vasculaire cérébral aigu (AVCA) suscite des inquiétudes, particulièrement en ce qui concerne son utilisation intempestive chez des patients présentant des symptômes semblables à ceux d'un AVCA comme expression d'un trouble somatoforme. Souvent le diagnostic de trouble somatoforme est tardif et les agents thrombolytiques, qui sont administrés à ces patients pour traiter ce qui semble être un AVCA, les soumettent à un risque d'hémorragie. Méthodes: Nous avons examiné le mode de présentation, les observations neurologiques et la décision thérapeutique chez 85 patients qui ont reçu du rtPA IVaprès un diagnostic d'AVCA. Tous les patients survivants ont subi un examen neurologique au moins 3 mois après l'administration de rtPA IV. Les tomodensitométries cérébrales faites initialement et au cours du suivi ont été révisées de nouveau par un neuroradiologiste qui ne connaissait pas le dossier clinique du patient. Les patients dont les constatations cliniques, la tomodensitométrie cérébrale et l'évolution neurologique ne concordaient pas avec un tableau anatomique et clinique connu ou attendu d'AVC ont subi une évaluation psychologique au moyen du MMPI-2. Résultats: Chez deux patients, trois épisodes ressemblant à un AVCAcomme manifestation d'un trouble somatoforme ont été traités par inadvertance au moyen de rtPA IV. Ceci résulte essentiellement d'un examen neurologique sommaire et d'un diagnostic différentiel restreint. Interprétation: Les patients atteints de trouble somatoforme peuvent consulter pour des symptômes qui ressemblent à ceux d'un AVCA. Vu les contraintes de temps inhérentes à l'utilisation du rtPA, le diagnostic de trouble somatoforme peut être manqué, exposant ces patients aux complications de la thrombolyse.

Can. J. Neurol. Sci. 2004; 31: 99-101

Patients with somatoform disorder present with multiple somatic complaints and manifestations which may mimic stroke syndromes. Incorrect diagnosis may lead to inappropriate use of a thrombolytic agent in such patients. ${ }^{1}$ Diagnosis of somatoform disorder is difficult and often delayed. ${ }^{2}$ Even a detailed neurological history and examination may miss a probable diagnosis of somatoform disorder. This possibility may increase further when the physician, faced with the short therapeutic time window for IVrt-PA, performs a hasty neurological examination and develops a limited differential diagnosis. To our knowledge, there are no reported cases of patients with stroke-like presentations of somatoform disorder receiving IV rt-PA.
The Minnesota Multiphasic Personality Inventory-2 (MMPI2) is often used to help differentiate organic disease from functional disorders. Although there are few studies to date that

From the Division of Neurology, Department of Medicine (MSM, JK, AS); Division of Clinical Psychology, Department of Psychiatry (JR); Faculty of Medicine (GJ); Faculty of Medicine, Queens University, Kingston, Ontario (JM); Division of Neuroradiology, Department of Radiology; University of Alberta (DJE); Department of Clinical neurosciences, University of Calgary, Alberta (AMD), Canada.

RECEIVED JANUARY 2, 2003. ACCEPTEDIN FINALFORM JUNE 25, 2003.

Reprint requests to: Ashfaq Shuaib, Division of Neurology, 2E3.13 WMC, University of Alberta, 8440 112th Street, Edmonton, AB T6G 2B7Canada. 
look at the MMPI-2 profiles of medically ill patients, Graham suggested that profiles of medical patients fall within the normal limits, with T-scores on scales 1 (hypochondriasis (Hs)), 2 (depression (D)), and 3 (hysteria (Hy)) falling between 55 and 60 and scores on the rest of the clinical scales falling near the mean. ${ }^{3}$ Osborne $^{4}$ summarized studies with the original MMPI. He concluded that patients whose symptoms were primarily psychological in origin tended to score higher on scales $1(\mathrm{Hs}), 2$ (D), and 3 (Hy) compared to patients with similar symptoms of an organic origin. Furthermore, the most common profile among those patients was a "V" profile with scales $1(\mathrm{Hs})$ and 3 (Hy) being more elevated than scale 2 (D). The likelihood of functional origin increased when scales 1 (Hs) and $3(\mathrm{Hy})$ were elevated above a score of T-65 and were considerably higher than scale 2 (D).

\section{METHOD}

The hospital charts and brain CT-scans of 85 patients who received IV rt-PA for acute stroke were reviewed as part of an auditing and follow-up program by a team of two neurologists and a neuroradiologist who were not involved with the acute management of the patient whose chart and imaging studies were being reviewed. The neuroradiologist was blinded to clinical presentation and outcome. All the surviving patients underwent neurological re-examination at least three months after thrombolytic therapy. Based on inconsistencies in the initial clinical presentation, follow-up neurological examination, and imaging studies, two patients were identified as possibly suffering from somatoform disorder. Both patients underwent psychological consented neurological reexamination, MMPI-2 testing and electroencephalography. Each case was further discussed with the physicians involved with their care at the time of acute presentation in order to understand further the acute presentation and the reasoning that led to thrombolytic treatment.

\section{Patient 1}

An 81-year-old right-handed woman with a past medical history of seizures and pseudoseizures was brought to the emergency room with an acute left arm and leg paralysis and sensory loss. Her neurological examination revealed full visual fields, severe dysarthria, paralysis and sensory loss on the left. Her National Institute of Health Stroke Scale score (NIHSS-score) was 13. Brain CTrevealed no changes attributable to acute stroke. This presentation was interpreted as an acute stroke in the right middle cerebral artery territory. Considering that she was within the three hour window, she was treated with IV rt-PA. Her symptoms completely resolved within six hours. The evening of her hospital stay she called the nurse to her bedside, became unresponsive and her eyes rolled up and down for a few minutes. Immediately thereafter, she regained a normal level of consciousness and told the nurse that she just had a seizure. There was no post-ictal state. During the next three months she made four more emergency room visits with similar claims of having a stroke. At one of these presentations she demanded thrombolytic therapy, and at another she demonstrated left-sided paralysis in the presence of physicians, but she was able to use her left arm when not under direct observation.

Following her last presentation, the MMPI-2 was administered and the patient provided a valid profile. All subscales were within the normal limits with the exception of scales 1 (Hs), 2 (D), and 3 (Hy). T-scores for scales 1 and 3 were greater than 65 and considerably higher than scale
2. The patient denied any recent stressors. This patient's profile was consistent with a diagnosis of conversion disorder.

\section{Patient 2}

A 52-year-old right-handed man with a history of depression was brought to the emergency room with sudden onset of left-sided paralysis and speech arrest. He was awake and oriented but anarthric, had full visual fields and demonstrated inconsistent and ever changing eye movement abnormalities, bilateral facial weakness, paralysis of all limbs, and sensory loss on the left. An NIHSS-score of 26 was given. Brain CT revealed no acute changes. He was clinically diagnosed with brainstem stroke. A decision was made to attempt intravenous and intraarterial rt-PA. As part of this protocol, a cerebral angiogram was performed revealing no clot or vascular pathology. He remained with weakness fluctuating from day to day. $\mathrm{He}$ was later referred to rehabilitation. Six months later, he presented with another acute episode identical to the first one, with the addition of trismus. The patient was examined by another set of physicians and underwent the same diagnostic and treatment steps with similar results. He was again transferred to rehabilitation with left sided deficits. Two months later at a stroke clinic follow-up, he continued to claim and demonstrate severe left sided weakness and diminished sensation on the left, which split right in the midline. He showed difficulty lifting his left arm and leg against gravity, but when asked, he was able to walk backward on his toes with his knees bent at 90 degrees and his hands held over his head. At a third presentation to the emergency room he was mute, unresponsive to verbal commands, and resisted attempts by the examiner to open his eyes or mouth. His left arm elevated over his face, gently dropped down to the bed. Brain CT showed no abnormality. He was admitted to the psychiatry unit. Two months later he was discharged with an axis I diagnosis of somatoform disorder, and axis II diagnosis of dependent traits.

The MMPI-2 test was administered and again a valid profile was provided by the patient. Scales 1 (Hs), 2 (D), and 3 (Hy) were elevated. This patient's profile was consistent with a diagnosis of hypochondriasis.

\section{DISCUSSION}

Within the narrow time window for thrombolytic treatment, rapid but accurate neurological assessment is essential when confronted with an acute stroke syndrome. ${ }^{4}$ We have summarized two patients with several presentations suggestive of acute vascular events where IV rt-PA was incorrectly given in three events. Both patients were later diagnosed with somatoform disorders. This is disconcerting in light of the serious hemorrhagic complications of rt-PA. ${ }^{5}$ Intracranial hemorrhage risk was $6.3 \%$ in the National Institute of Neurological Disorders and Stroke trial. Interestingly, 20\% of all rt-PA related symptomatic hemorrhages $(1.3 \%$ of all rt-PA treated patients) occurred in a vascular territory outside of the presenting stroke. ${ }^{6}$ Although higher rt-PA doses and addition of heparin and or aspirin were used in thrombolytic therapies for myocardial infarction, hemorrhagic strokes occurred in $0.95 \%$ of these patients. ${ }^{7}$

Both of our patients presented with recurring events. Missing the diagnosis of a somatoform disorder may have contributed to reinforcing the patients'symptoms and thus propagating further symptoms and delayed appropriate treatment.

Screening questionnaires for somatization disorder have been 
developed. Patients with a history of three or more symptoms of shortness of breath, dysmenorrhea, burning in sex organs, lump in throat, amnesia, vomiting and painful extremities are at risk for somatization disorder. ${ }^{8}$ Neurologists often use Weintraub's physical signs of hysteria including la belle indifference, sensory loss not conforming to anatomical patterns, changing patterns of sensory loss, alterations of sensory and motor findings with suggestion, hemianesthesia that splits the midline, unilateral loss of vibratory sense when two sides of forehead or sternum are stimulated and give away weakness on motor testing. ${ }^{9}$ The validity of such signs has been questioned. ${ }^{10}$ While waiting for laboratory results, there is sufficient time to more carefully ascertain such neurological findings and identify whether the stroke syndrome reflects the suspected vascular territory. In the future, more advanced imaging techniques such as diffusion perfusion MRI may aid the identification of those whose clinical presentation cannot be explained anatomically.

Besides somatoform disorder, other neurological disorders such as seizures, multiple sclerosis, migraine aura, and brain tumors may have acute stroke-like presentations. It is possible that our patients experienced transient ischemic attacks (TIAs), which may explain why follow-up brain CT failed to demonstrate a lesion compatible with stroke. Given the reoccurrence of identical symptoms and inconsistencies in neurological examination, the possibility of TIAs is remote. Postictal state is a consideration in the first patient. However, no seizure activity or postictal changes were demonstrated on EEG, and recovery from presumed generalized seizures was rapid and complete, making seizures unlikely.

In the emergency room, somatoform disorder is a diagnosis of exclusion. Careful self-auditing by acute stroke programs may help to distinguish patients with acute stroke from those with somatoform disorders. This may help to develop distinct patient profiles to prevent inadvertent use of thrombolytic therapy. However, it is important to emphasize that even patients with a previous diagnosis of somatoform disorder need to be accurately assessed each time they present with an acute stroke-like syndrome. Like the general population, people with somatoform disorder still remain at risk for stroke.

\section{REFERENCES}

1. Caplan L, Mohr JP, Kistler JP, Koroshetz W. Should thrombolytic therapy be the first-line treatment for acute ischemic stroke? Thrombolysis - not a panacea for ischemic stroke. New Engl J Med 1997; 337:1309-1310.

2. Diagnostic and Statistical Manual of Mental Disorders, 4th ed. Somatization disorders. Washington, DC: American Psychiatric Association 1994.

3. Graham J. MMPI-2: Assessing Personality and Psychopathology. New York, NY: Oxford University Press, 1990:194-195.

4. Osborne D. Use of the MMPI with medical patients. In: Butcher JN (Ed.) New Developments in the Use of the MMPI. Minneapolis: University of Minnesota Press, 1979:141-163.

5. NINDS rt-PA Stroke Study Group. Tissue plasminogen activator for acute ischemic stroke. N Engl J Med 1995; 333:1581-1587

6. NINDS rt-PA Stroke Study Group. Intracerebral hemorrhage after intravenous t-PA therapy for ischemic stroke. Stroke 1997; 28:2109-2118.

7. Gurwits J, Gore J, Goldberg R, et al. Risk for intracranial hemorrhage after tissue plasminogen activator treatment for acute myocardial infarction. Ann Intern Med 1998: 129:597-604.

8. Othmer E, DeSouza C. A screening test for somatization disorder (hysteria). Am J Psychiatry 1985: 10:1146-1149.

9. Weintraub MI. Hysterical conversion reactions. A clinical guide to diagnosis and treatment. Clinical presentation in adults. New York: SPMedical and Scientific, 1983:41-104

10. Gould R, Miller B, Goldberg M, Benson F. The validity of hysterical signs and symptoms. J Nerv Ment Dis 1986: 174(10): 593-597. 